were just significantly higher than those obtained at 30 minutes after either an eight-hour or a 16-hour fast. Nevertheless, the subsequent values obtained after the four-hour fast were similar to those after the other periods of fasting. Thus in the biological sense there was no impairment of carbohydrate tolerance after the four-hour fast.

We think that waking the patients at 0500 in the study of Walsh et $a^{1}$ may have influenced the results they obtained. We suggest that in further studies hormone concentrations, particularly those of plasma cortisol, should be measured in addition to blood glucose concentrations. We think that our results indicate that by itself the duration of the pretest fast does not affect tolerance of oral glucose.

${ }^{1}$ Walsh, C H, O'Regan, J, and O'Sullivan, D J, British Medical fournal, $1973,2,691$

2 Jarrett, R J, and Keen, H, British Medical fournal, 1969, 2, 341.

(Accepted 8 December 1977)

Departments of Medicine and Gastroenterology and Pathology,

The Charitable Infirmary, Dublin 1, Ireland

J F FIELDING, MD, MRCP, physician

HELEN TOOMEY, MSC, biochemist

\section{Idiopathic nephrotic syndrome: prevention of early relapse}

In children with the idiopathic nephrotic syndrome early relapses are often due to adrenocortical suppression after prednisone. ${ }^{12}$ We have shown that such early relapses can be avoided by partial cortisol substitution.

\section{Patients, methods, and results}

Eight boys and five girls (aged 4.7-14.6 years) who had had glucocorticoidsensitive idiopathic nephrotic syndrome for up to $10 \cdot 3$ years were studied after their parents had given informed consent. The clinical definitions and prednisone regimen have been described elsewhere. ${ }^{3}$ A two-hour ACTH test $^{4}$ was performed 1-12 days after treatment. Children with subnormal responses ${ }^{4}$ were allotted to group 1 (drug sequence $A-B$ ) or group 2 (sequence $B-A)$. Drugs $A$ and $B$ were tablets of identical appearance and taste, A

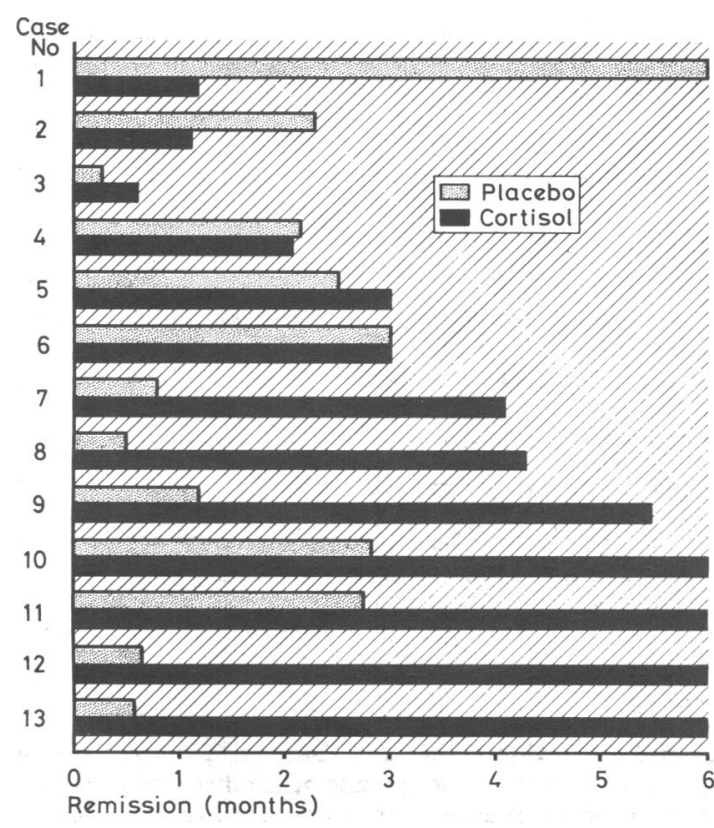

Length of remissions in 13 nephrotic children with postprednisone adrenocortical suppression. Periods of partial cortisol substitution and placebo medication are compared. containing $5.0 \mathrm{mg}$ cortisol and B without the active agent. Their identity was not known to anyone concerned in the study. Children weighing $30 \mathrm{~kg}$ or more took two tablets at 7 am and one tablet at $2 \mathrm{pm}$; smaller children were given half the dose. When infection or detectable proteinuria (urine was checked at home every morning with Albustix) occurred the daily dose was doubled and given in equal parts every six hours over the next three days or until the symptoms had disappeared. The first drug was continued for six months or until relapse. As soon as the child again had post-prednisone adrenocortical suppression after a relapse, the second drug of the sequence was started. In six children the ACTH test was performed on completion of each drug period.

Twenty-one of the 26 drug periods had to be interrupted because of relapse (see figure). At three months eight children remained in remission during the cortisol period only, one child in the placebo period only, and one child during both periods. The difference was significant at the $5 \%$ level $\left(\gamma^{2}=4 \cdot 0\right)$. At six months five remissions continued, four of them during the cortisol period. Three of these children were followed for a full year and all relapsed. The fifth six-month remission was observed in case 1 during a placebo period; subsequent $2 \cdot 4$-year follow-up indicated that the idiopathic nephrotic syndrome had been cured. The following variables were compared between the cortisol and placebo periods with Student's paired $t$ test: the extent of pre-prednisone proteinuria; pre- and post-prednisone plasma concentrations of albumin, protein, cholesterol, and urea nitrogen; length of prednisone treatment; and post-prednisone and post-substitution ACTH test responses. No differences were significant. The effectiveness of cortisol substitution was independent of age and sex.

\section{Comment}

The results of this double-blind cross-over study indicate that partial cortisol substitution prevented half the relapses predictable within three months of remission. This supports the hypothesis that post-prednisone hypocortisolism is responsible for many of the early relapses in the idiopathic nephrotic syndrome. ${ }^{12}$ Many frequent relapsers are in a continuous cycle of relapse-prednisone treatmentadrenocortical suppression-relapse. ${ }^{2}$ Children with adrenocortical suppression should be identified and temporarily provided with partial cortisol substitution. This has to be partial; otherwise the suppression will persist. Our present regimen seems to be appropriate.

We thank the Sigrid Jusélius Foundation for generous support and AB Medica OY, Helsinki, for the drug preparations.

${ }^{1}$ Leisti, S, et al, Lancet, 1977, 2, 795.

2 Leisti, S, Vilska, J, and Hallman, N, Pediatrics, 1977, 60, 334.

${ }^{3}$ Abramowicz, M, et al, Lancet, 1970, 1, 959.

4 Leisti, S, Clinical Endocrinology, 1977, 6, 305.

(Accepted 6 December 1977)

Children's Hospital, University of Helsinki, SF-00290 Helsinki 29, Finland

S LEISTI, MD, instructor

O KOSKIMIES, MD, lecture

J PERHEENTUPA, MD, associate professor

J VILSKA, MD, paediatrician

N HALLMAN, MD, professor

\section{Persistent orthostatic hypotension after epidural analgesia}

Some degree of hypotension normally occurs during epidural blockade, but is transient. In the case reported here, however, severe orthostatic hypotension persisted for many weeks. This complication of epidural analgesia has not been reported.

\section{Case report}

A 26-year-old primipara was admitted ten days after the expected date of delivery. She had been well throughout pregnancy, with normal blood pressure, no postural symptoms, and no evidence of gestational diabetes. Labour was induced by artificial rupture of the membranes, and soon after the patient requested epidural analgesia. A catheter was inserted through a Tuohy needle at the level of L 2-3, the epidural space being identified by loss of resistance. The anaesthetist was experienced in the technique, and the dura was not punctured. A test dose of $2 \mathrm{ml}$ lignocaine $(1.5 \%)$ was administered with the patient in the left lateral position, followed by a further $10 \mathrm{ml}$. 
Thereafter analgesia was maintained with bupivacaine $(0.375 \%)$, a total of $28 \mathrm{ml}$ being given in three divided doses. Neither local anaesthetic solution contained adrenaline. A live baby girl was delivered spontaneously after eleven hour's labour. Analgesia was satisfactory, apart from an area in the right groin. The lowest blood pressure recorded during labour was $90 / 60 \mathrm{~mm}$ $\mathrm{Hg}$, when the patient was on her side.

During the next few days she complained of headache, dizziness, and nausea, particularly when out of bed. Nevertheless, her symptoms seemed to be settling, and she was discharged a week after delivery. She was seen again as an outpatient six weeks later. She reported that on standing she developed a severe throbbing headache and faintness, relieved by lying down She had been breast-feeding her baby, and doing the housework on all fours. The results of clinical examination in the supine position were unremarkable, with normal papillary responses and no evidence of a peripheral neuropathy or spinal cord lesion. Supine blood pressure was $115 / 75 \mathrm{~mm} \mathrm{Hg}$, with a pulse rate of $80 /$ minute. On standing, however, she developed her symptoms and within two minutes her blood pressure fell to $70 / 50 \mathrm{~mm} \mathrm{Hg}$ with a tachycardia of $136 /$ minute. Postural changes of this magnitude occurred consistently; there was no bradycardia after the Valsalva manoeuvre. Sweating was assessed using quinizarin as an indicator. ${ }^{1}$ It occurred on the face (sudomotor innervation $\mathrm{T} 2-\mathrm{T} 4$ ) and partially on the arms (T 2-T 8), but was absent on the trunk (T 6-T 10) and legs (T 11- L2). Sweating could be induced in the anhidrotic areas as a local axon reflex, by intradermal injection of acetylcholine.

No other member of the family suffered from postural hypotension. The patient did not have biochemical evidence of diabetes or porphyria, the serum electrolyte concentrations were normal, and the results of serological tests for syphilis were negative. Ampoules of the local anaesthetic agents from the same batches were administered to other patients without ill effect.

\section{Comment}

The findings in this patient point to a lesion of the preganglionic efferent sympathetic pathways below the mid-thoracic region, resulting in orthostatic hypotension. Her symptoms date from epidural analgesia, and have persisted for over three months; she still requires fludrocortisone to control them. Analgesia during epidural block with bupivacaine commonly extends to the level of T9. ${ }^{2}$

Animal studies ${ }^{3}$ support the clinical evidence that the level of sympathetic block extends several segments cephalad. This patient must have had an idiosyncratic response to the local anaesthetic, resulting in persistent sympathetic dysfunction.

We thank Dr P Millac and Dr S W Theophilus for permission to report this case.

1 Karat, A B, Karat, S, and Pallis, C A, Lancet, 1969, 1, 651.

2 Crawford, J S, British fournal of Anaesthesia, 1972, 44, 66.

${ }^{3}$ Heavner, J E, and de Jong, R H, Anesthesiology, 1974, 40, 228.

(Accepted 11 December 1977)

Leicester Royal Infirmary, Leicester LE1 5WW

R S BRIGGS, MB, MRCP, registrar in neurology

A E MAY, MB, FFARCS, senior registrar in anaesthesia

$M$ I GERGIS, MB, DA, registrar in anaesthesia

\section{Dengue shock syndrome in Jamaica}

In South-east Asia and the western Pacific severe dengue characterised by shock and haemorrhage has become a major cause of death. ${ }^{1}$ In a current epidemic in Jamaica dengue shock syndrome and dengue haemorrhagic fever have been seen for the first time.

\section{Case 1}

A 42-year-old woman was admitted to hospital with a three-day history of fever, rigors, headache, retro-orbital, chest, and back pain, vomiting, and fainting. She was confused and restless, her temperature subnormal $\left(35.5^{\circ} \mathrm{C}\right)$, and the periphery cold and clammy. Her pulse was $112 / \mathrm{min}$ and weak, blood pressure $90 / 0 \mathrm{~mm} \mathrm{Hg}$, and respiratory rate $40 / \mathrm{min}$ and shallow. Central venous pressure (CVP) was $+2 \mathrm{~cm} \mathrm{H}_{2} \mathrm{O}$.

An electrocardiogram showed low voltages, $\mathrm{S}-\mathrm{T}$ depression and $\mathrm{T}$-wave inversion. Haemoglobin was $15.7 \mathrm{~g} / \mathrm{dl}$ (subsequently $11.3 \mathrm{~g} / \mathrm{dl}$ ) and blood urea $13 \mathrm{mmol} / 1(78 \mathrm{mg} / 100 \mathrm{ml})$ (subsequently $3.6 \mathrm{mmol} / 1(22 \mathrm{mg} / 100 \mathrm{ml})$ ) suggesting considerable haemoconcentration. White blood cell count (WBC) was $15.4 \times 10^{9} / 1$ (neutrophils $83 \%$ ); platelets, prothrombin time, partial thromboplastin time were normal; aspartate aminotransferase (SGOT) was $35 \mathrm{IU} / 1$ and alanine aminotransferase (SGPT) $40 \mathrm{IU} / 1$ and alkaline phosphatase normal. There was proteinuria $(0.05 \mathrm{~g} / 24 \mathrm{~h})$. Sputum, urine, and blood cultures were negative. Dengue haemagglutination inhibition (HI) was $1 / 160$ on day 5 and $1 / 640$ on day 19 . The table shows the complement profiles.

With intravenous fluid therapy the blood pressure and temperature rose to $110 / 70 \mathrm{~mm} \mathrm{Hg}$ and $37 \cdot 9-38 \cdot 3^{\circ} \mathrm{C}$ respectively after three days. On day 6 a desquamating rash appeared on the face and neck and pulmonary oedema developed, requiring treatment with frusemide. Further progress was uneventful.

\section{Case 2}

A 30-year-old woman was admitted with a 10-day history of fever, headache, retro-orbital pain, generalised myalgia, and bone pain. Transient improvement after seven days was followed by episodes of fainting, vomiting, and abdominal pain radiating to the back.

When seen she was in circulatory failure, the temperature $36^{\circ} \mathrm{C}$, pulse $100 / \mathrm{min}$, blood pressure $70 / 60 \mathrm{~mm} \mathrm{Hg}$, respiratory rate $28 / \mathrm{min}$, and CVP $-8 \mathrm{~cm} \mathrm{H}_{2} \mathrm{O}$. She was jaundiced and her abdomen distended, with tenderness in both upper quadrants, rebound tenderness, and shifting dullness. There was tender hepatomegaly of $3 \mathrm{~cm}$.

Haemoglobin was $14.7 \mathrm{~g} / \mathrm{dl}$, falling to $9.5 \mathrm{~g} / \mathrm{dl}$ in five days; WBC $17.9 \times$ $10^{9} / 1$ (neutrophils $78 \%$ ); platelets $146 \times 10^{9} / 1$; prothrombin time $22 \mathrm{~s}$ (control 12.5 s); partial thromboplastin time $48 \mathrm{~s}$ (control $39 \mathrm{~s}$ ); urea $7 \cdot 2$ $\mathrm{mmol} / 1(43 \mathrm{mg} / 100 \mathrm{ml})$, falling to $4.0 \mathrm{mmol} / 1(24 \mathrm{mg} / 100 \mathrm{ml})$ over five days; bilirubin $86 \mu \mathrm{mol} / 1(5 \mathrm{mg} / 100 \mathrm{ml})$; alkaline phosphatase normal; SGPT $120 \mathrm{IU} / 1$, urinary amylase $869 \mathrm{IU} / 24 \mathrm{~h}$, serum protein $64 \mathrm{~g} / \mathrm{l}$, albumin $29 \mathrm{~g} / 1$, globulin $35 \mathrm{~g} / \mathrm{l}$, ascitic fluid protein $39 \mathrm{~g} / \mathrm{l}$, albumin $20 \mathrm{~g} / \mathrm{l}$, and globulin $19 \mathrm{~g} / \mathrm{l}$. Urine and blood cultures and leptospira agglutination titres were negative. Dengue HI was $1 / 640$ at day 10 and on day 22. Complement profiles are shown in the table.

She was treated with intravenous fluids, plasma, metoclopramide, and pethidine. Nasogastric aspiration yielded "coffee-grounds" fluid. Her temperature rose to $39.5^{\circ} \mathrm{C}$ on the day after admission and remained raised for five days. The abdominal tenderness and ascites resolved over seven days, but upper abdominal pain continued for two weeks. She had severe diarrhoea on the second and third days in hospital. Weakness and faintness also continued and her blood pressure was subnormal until the third week.

\section{Comment}

In 1963 and 1968 Jamaica experienced epidemics of dengue caused by serotypes 2 and 3.2 ${ }^{2}$ Type 1 virus has been isolated during the current epidemic. The four dengue serotypes share common antigens, and reinfection with a different serotype results in high titres of nonprotective antibody early in the illness. It has been postulated that (a) such antibody may react with the different serotype, producing immune complexes which activate the complement system and possibly produce shock ${ }^{3}$; and (b) pre-existing antibody bound on lymphoid cell membranes may facilitate intracellular virus infection and replication. ${ }^{4}$

Our patients, both adults, had dengue shock syndrome as defined by Halstead. ${ }^{5}$ The second also had haemostatic abnormalities and hepatitis, seen in dengue haemorrhagic fever; and she also had pancreatitis, not previously described in dengue. The low concentrations of complement components with normal IgG and transferrin and the presence of $\mathrm{C} 3 \mathrm{~d}$ (a C3 metabolite) in blood (case 1) suggest

Serum protein concentrations (radial immunodiffusion assay) in cases 1 and 2. Concentrations of complement components C1q to C5 are expressed as \% normal human pooled serum

\begin{tabular}{|c|c|c|c|c|c|c|c|c|c|}
\hline Case No & $\mathrm{Clq}$ & $\mathrm{C} 4$ & B & C3 & C3dt & C5 & $\mathrm{CH}_{50}$ units & $\underset{(\mu \mathrm{g} / \mathrm{l})}{\text { Transferrin }}$ & $\underset{(\mathbf{g} / \mathbf{l})}{\mathrm{IgG}}$ \\
\hline $\begin{array}{c}1 \\
2 \\
\text { Normal* }\end{array}$ & $\begin{array}{c}100 \\
37 \\
60-150\end{array}$ & $\begin{array}{c}82 \\
210 \\
52-170\end{array}$ & $\begin{array}{c}56 \\
86 \\
66-124\end{array}$ & $\begin{array}{c}58 \\
74 \\
77-115\end{array}$ & $\begin{array}{c}\text { Present } \\
\text { Nil } \\
\text { Nil }\end{array}$ & $\begin{array}{c}58 \\
48 \\
76-124\end{array}$ & $\begin{array}{c}890 \\
980 \\
1050-1700\end{array}$ & $\begin{array}{c}2 \cdot 8 \\
2 \cdot 6 \\
2 \cdot 2-3 \cdot 3\end{array}$ & $\begin{array}{c}16 \cdot 0 \\
12 \cdot 0 \\
11 \cdot 0-18 \cdot 0\end{array}$ \\
\hline
\end{tabular}

*Normal values for our laboratory. †C3d was measured in EDTA plasma by immunoelectrophoresis. 